Original Research Paper

\title{
Credibility of 3D Volume Computation Using GIS for Pit Excavation and Roadway Constructions
}

\author{
${ }^{1,2}$ Ragab Khalil \\ ${ }^{I}$ Department of Civil Engineering, Faculty of Engineering, Assiut University, Assiut, Egypt \\ ${ }^{2}$ Department of Landscape Architecture, Faculty of Environmental Design, KAU, Jeddah, Saudi Arabia
}

Article history

Received: $17-08-2014$

Revised: 02-03-2015

Accepted: 24-08-2015

Email: khalilragab@yahoo.com

\begin{abstract}
Volume estimation and earthworks calculation of borrow pits and roadway constructions are typical applications in civil Engineering. Although several methods for volume estimation were introduced, the average end area method still the common method used by owners and contractors. Average end area method is tedious and time consuming. Volume of terrains that do not have regular geometric structure can be obtained more accurately by using 3D models of surfaces with respect to developing technology such as GIS. The gridding method and point distribution are important factors in modeling earth surfaces used for volume estimation. In this study the credibility of $3 \mathrm{D}$ volume estimation based on raster GRID or Triangular Irregular Network (TIN) using GIS was investigated. The effects of interpolation method and point distribution in defining a terrain surface were also investigated. For this purpose, an artificial surface with a known volume that used by Chen and Lin in their paper is employed. The 3D surface and volume are calculated for both surfaces represented by TIN and GRIDs generated by using 6 different interpolation methods. The resultant volumes were compared to the exact volume and to that estimated by using average end area method. Moreover a comparison between cut and fill volumes needed for grading the study cases at a certain elevation was done. The results show that for gentle slope surface, TIN and all interpolation techniques gave results very close to the exact except Kriging and Trend interpolation. For steep slope terrain, Kriging interpolation gave the best results. Comparing earthwork volume to the average end area method, TIN surface, IDW, Topo to raster and Nearest Neighbor methods gave the best results.
\end{abstract}

Keywords: 3D Volume, GIS, Grid, TIN, Interpolation, Average End Area

\section{Introduction}

As an important engineering application, volume calculation is used in various fields such as reserve estimation of mine sites and determination of the excavation and earth fill for sites such as roads, airports and tunnels (Yilmaz, 2009). Reliable and accurate earthwork volume calculation was the target of many authors through the past 30 years. Different mathematical models were suggested by Easa (1988; Chambers, 1989; Chen and Lin, 1991; Davis, 1994; Easa, 1998; Yanalak, 2005; Yilmaz, 2010; Mukherji, 2012; Khalil, 2014) to estimate the volume of pit excavation. Earthwork calculation for roadway construction was also investigated by many researchers. Mayer and Stark (1981; Epps and Corey, 1990; Easa, 1992a; 1992b; Moreb, 1996; Kim and Schonfeld, 2001; Easa, 2003; Goktepe and Lav, 2003) developed methods for roadway earthwork calculation in 2D depending on using average end area or improvements in it. The 3D concept was used by Du and Teng (2007; Bao, 2011; Kerry et al., 2012; Bhatla et al., 2012) where a digital Elevation Model (DEM) was created for the surface then a Triangular Irregular Network (TIN) was generated and earthwork quantities were computed by comparing the TIN of original terrain to that of the finished project. 
The 2D methods such as average-end-method, prismoidal formula and other models improved based on them, are not accurate in theory but practically used in engineering. The concept of adopting average-endarea method is deep-rooted in roadway design. According to an investigation in US, most state highway agencies still use, or even specify, the average-end-area method (Hintz and Vonderohe, 2011) and 87 and $91 \%$ designers use average-end-area for design estimates and final quantities respectively and $97 \%$ of the respondents recognize average-end-area in their policies, standards and procedural documents (Cheng and Jiang, 2013).

Geographic Information System (GIS) technologies support the representation of existing ground, design and final as-built surfaces that can be overlaid and differenced to obtain volumes. ArcGIS 10 software has many tools to calculate earthwork volume in $3 \mathrm{D}$ based on TIN or grids which generated directly or through interpolation of cross sections data.

This paper verifies the feasibility of calculating the earthwork volume in 3D method by using ArcGIS software based on TIN or GRID and compares the accuracy to both the exact volume and the volume computed by using average end area method for the reference of practical engineering. Moreover the accuracy of gridding methods available in ArcGIS will be investigated to determine the best one for practical use.

\section{Methodology}

The general procedure involves: (1) Data preparation for the different study cases; (2) generation of TIN and raster grid surfaces; (3) estimation of triangulated and gridded volumes; and (4) summary statistics on the outcomes.

The data of Example 2 of Chen and Lin (1991) was used in this research. Data for four study cases were prepared using Microsoft Excel. To compute volume using GIS, the cross section data was used to generate TIN and raster GRIDs for each study case. The raster grids were generated using Inverse Distance Weight (IDW), Kriging, Natural Neighbor, Spline, Topo to Raster and Trend interpolation methods. A comparison between the exact volume, average end area volume and the volume estimated under each TIN or GRID surface was performed. Moreover a comparison between cut and fill volumes needed for grading the study cases at a certain elevation was done. Figure 1 shows the steps and tools used to generate surfaces and compute excavation and cut and fill volumes.

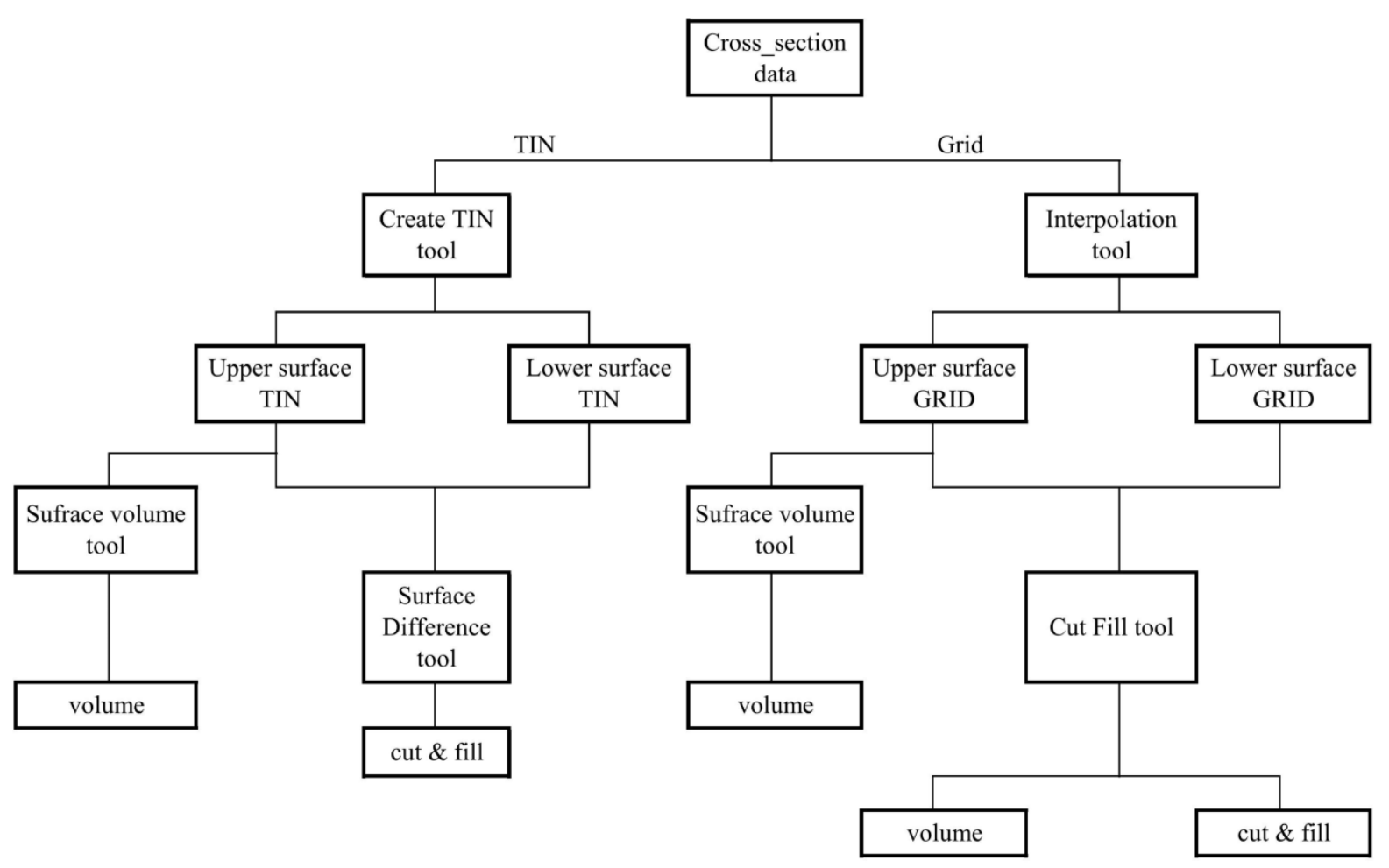

Fig. 1. Steps for volume estimation using TIN and raster GRID 


\section{Interpolation Methods}

There are two categories of interpolation techniques: Deterministic and geostatistical. Deterministic interpolation techniques create surfaces based on measured points or mathematical formulas. Geostatistical interpolation techniques are based on statistics and are used for more advanced prediction surface modeling that also includes some measure of the certainty or accuracy of predictions (Childs, 2004).

The IDW approach is a local deterministic interpolation technique that calculates the value as a distance-weighted average of sampled points in a defined neighborhood (Arun, 2013 after Burrough and McDonnell, 1998). It is based on the premise that the predictions are a linear combination of available data (Xie et al., 2011). It weights the sample points with inverse of their distance from the required point, so points closer to the query location will have more influence. The IDW function should be used when the set of points is dense enough to capture the extent of local surface variation needed for analysis (Childs, 2004).

Kriging is a geostatistical interpolation method that utilizes variogram which depends on the spatial distribution of data rather than on actual values. Kriging weights are derived using a data driven weighting function to reduce the bias toward input values and it provides the best interpolation when good variogram models are available. Kriging includes several methods such as ordinary Kriging, which is the most common method, block Kriging, coKriging, universal Kriging and disjunctive Kriging (Taylor et al., 2001).

Natural Neighbor Interpolation (NNI) has been introduced by Sibson for interpolating multivariate scattered data (Boissonnat and Cazals, 2001). It is a local deterministic method and interpolated heights are guaranteed to be within the range of the samples used. With this method, the data on the reference points with irregular distribution are classified and the interpolation process is completed using the Triangular Irregular Network (TIN) functions without any need for custom-defined parameters (Yilmaz, 2009). NNI takes the best of Thiessen polygons and triangulation and objectively chooses the number of neighbors from which to interpolate based on the geometry. The weights for each station are selected based on the proportional area rather than distance. NNI produces an interpolated surface that has a continuous slope at all points, except at the original input points. It is an exact interpolator in that it reproduces the observations at the station locations (Hofstra et al., 2008).

The Spline interpolation approach uses mathematical function to minimize the surface curvature and produces a smooth surface that exactly fits the input points.
Splines are piece-wise functions that consider few points at a time, which makes them rapid interpolators (Perlavo, 2004). According to the selected GIS package ArcGIS by ESRI, only two Splines were available: The Regularized and the Tension one. The Regularized Spline creates a smooth, gradually changing surface. The Tension Spline creates a less smooth surface with values more constrained by the sample data range (Garnero and Godone, 2013).

The Topo to Raster method is based on the ANUDEM method which uses an interpolation technique specifically designed for the creation of hydrologically correct terrain surfaces (Hutchinson, 1989). The interpolation algorithm was designed to have the computation efficiency of local methods and the continuity in the interpolated surface generated by global methods (Perlavo, 2004).

The Trend interpolation uses a global polynomial interpolation that fits a smooth surface defined by a mathematical function (a polynomial) to the input sample points. Polynomial is not really an interpolator because it does not attempt to predict unknown $\mathrm{Z}$ values (Yilmaz, 2007). The trend surface changes gradually and captures coarse-scale patterns in the data. The most common orders of polynomials are one through three. Trend surface interpolation creates smooth surfaces but it is not an exact interpolator (Yilmaz, 2009).

\section{Application}

The data of Example 2 of Chen and Lin (1991), which was the benchmark example used by Easa (1998; Yanalak, 2005; Mukherji, 2012; Khalil, 2014) were used for this application, because the purpose of this paper was to compare volumes resultant from GIS gridding methods with exact volume and with the volume of average end area. The example in Chen and Lin (1991) involved a pit whose ground surface is expressed with the function:

$$
z=f(x, y)=(20+y) / \sqrt{x}
$$

where, $1 \leq x \leq 121$ and $1 \leq y \leq 91$ (values are in meters) with exact volume $=118800 \mathrm{~m}^{3}$.

There are four cases for constructing the data grid as shown in Fig. 2. The first three cases were suggested by Chen and Lin (1991), the forth case was suggested by Mukherji (2012). These four cases were used to investigate the effect of point distribution on computed volume accuracy:

- A $6 \times 5$ grid with equal intervals in the (x) directions $(20 \mathrm{~m})$ but with unequal intervals in the (y) direction $(25,10,30,15,10 \mathrm{~m})$ 
- A $6 \times 5$ grid with equal intervals in the (y) directions $(18 \mathrm{~m})$ but with unequal intervals in the $(\mathrm{x})$ direction $(15,30,10,35,10,20 \mathrm{~m})$

- A $6 \times 5$ grid with unequal intervals in both the $(x)$ and (y) directions, $(\mathrm{x})$ intervals as described in cases 2 and $(\mathrm{y})$ intervals as in case 1

- A $10 \times 2$ grid with closer spacing in the $\mathrm{x}$-direction especially in the first $15 \mathrm{~m}$ where the surface changes dramatically. $\Delta \mathrm{x}=2 @ 2.5,2 @ 5,2 @ 15$, 2@22.5,2@15, $\mathrm{y}=2 @ 45$

In this study, beside the TIN surfaces that generated for the four study cases, all the interpolation methods were performed for raster grid generation using the module of $3 \mathrm{D}$ analyst in ARCGIS 10 with the default parameters. For IDW, the power is 2 , the search radius is variable and the maximum number of the researched points is 12 . For Kriging, ordinary method is selected, the model of semivariogram is
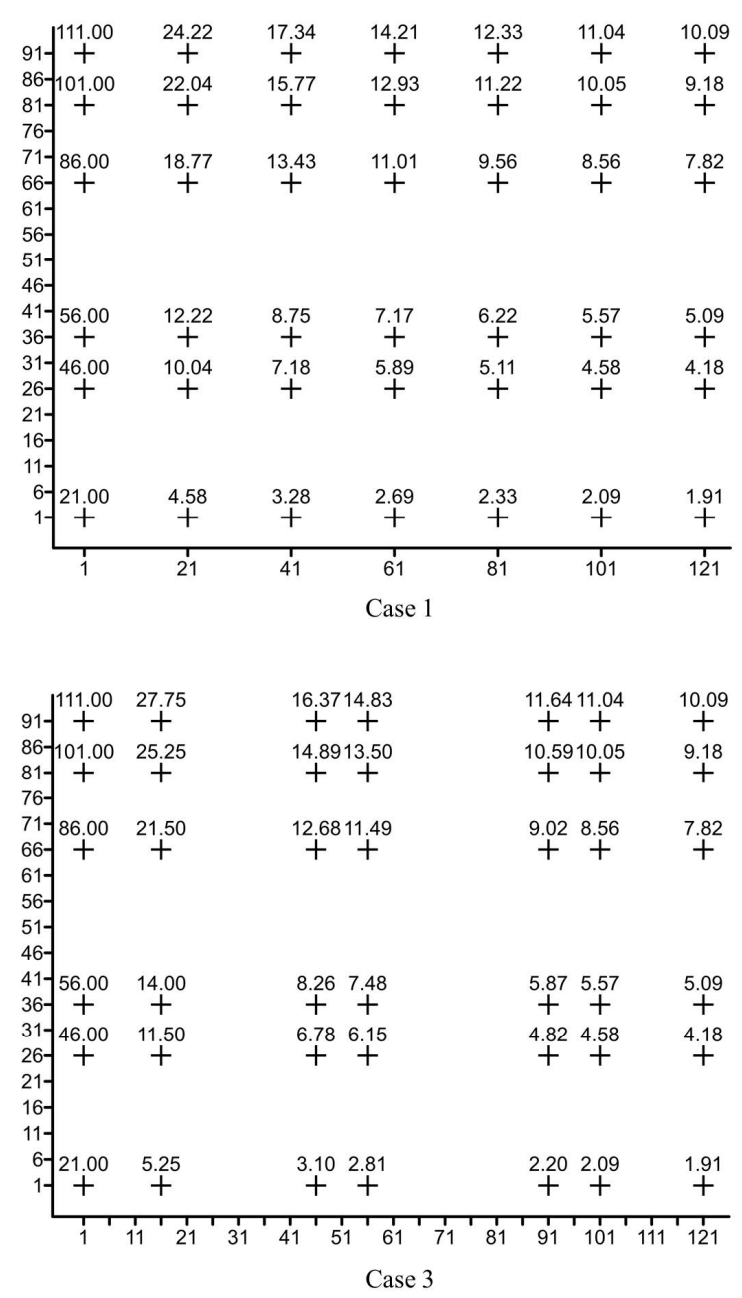

spherical, the searched radius is variable and the maximum number of the searched points is 12 . For Natural Neighbor, there were no parameters to select. For Spline, the regularized option is used, the weight is 0.1 and the number of the researched points is 12 . For Topo to Raster, the margin in cells is 20, the enforced drainage is selected, maximum number of iterations is 40, discretization error factor is 1 and the vertical standard error is 0 . For Trend, the polynomial order is 3 and the type of regression is linear.

The volume of the study cases were computed by using the previously mentioned interpolation methods. The results of volume and accuracy percentage rate to the exact value are given in Table 1 so that the results can be compared easily. The approach rate percentage was calculated using Equation 2:

App. rate $=\left(1-\left|\frac{V_{\text {Exact }}-V_{\text {computed }}}{V_{\text {Exact }}}\right|\right) * 100$
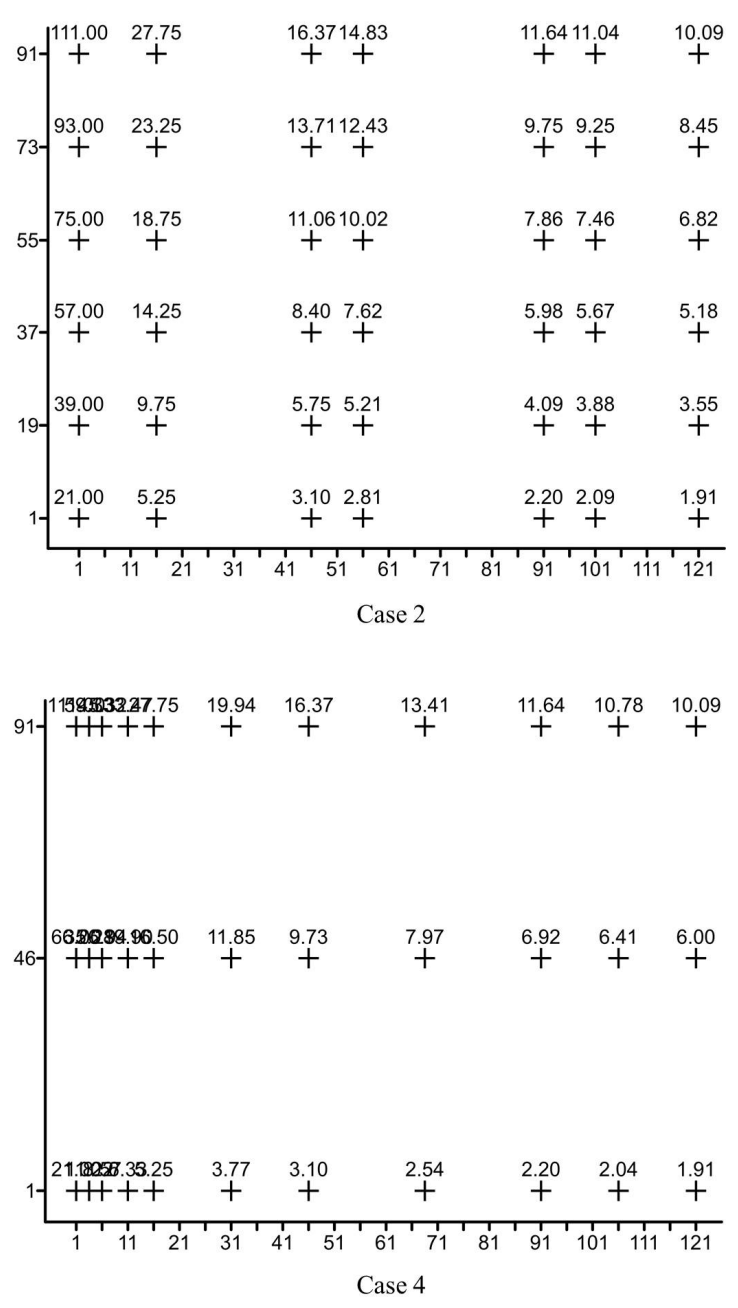

Fig. 2. Grids for application example (cases 1, 2, 3 and 4) 
According to Table 1, the following results can be outlined for the calculations handled in this study:

- For case 1 , the best results for volume calculation were obtained from Kriging interpolation (91.3\%) and spline interpolation $(89.9 \%)$. The worst result was obtained from IDW method $(70.5 \%)$. The rest of interpolation methods achieved rates between (72 and $75 \%$ ); Topo to Raster method was the best of them with accuracy rate of $(75.0 \%)$

- For case 2, the best results for volume calculation were obtained from spline interpolation $(92.2 \%)$ and Kriging interpolation (91.8\%). The worst result was obtained from IDW method $(77.7 \%)$. The rest of interpolation methods achieved rates between (79 and $83 \%$ ); Topo to Raster method was the best of them with accuracy rate of $(83.6 \%)$

- $\quad$ For case 3, the results are almost as that of case 2 . The best results for volume calculation were obtained from Kriging interpolation $(95.5 \%)$ and Spline interpolation $(92.2 \%)$. The worst result was obtained from IDW method $(77.2 \%)$. The rest of interpolation methods achieved rates between (79 and $85 \%$ ); Topo to Raster method was the best of them with accuracy rate of $(85.4 \%)$

- For case 4 , the best results for volume calculation were obtained from Trend interpolation (98.8\%), TIN method (98.4) and Average End Area (98.0\%). The worst result was obtained from Spline interpolation $(49.4 \%)$. The rest of interpolation methods achieved rates between (80 and 91\%); Topo to Raster method was the best of them with accuracy rate of $(91.2 \%)$

- The Trend interpolation produced negative volume because third-order polynomial fits the surface with two bends to each neighborhood

- As the points were chosen to represent the variations in the surface (case 4), the accuracy of all method was increased except the Spline interpolation. This may be due to the spline interpolation is sensitive to the points density

- Kriging and Spline interpolation underestimate the volume while the rest of the methods overestimate the volume for cases 1, 2 and 3. For case 4 all methods overestimate the volume

- As an average for the four cases, Kriging (91\%) is the best while the IDW (76\%) is the worst method, the rest of methods are almost the same with (83\%) accuracy rate

- It is not recommended to use Trend and Spline interpolation methods for volume calculations

- The average end area gave results close to the exact when the cross section points represent the variations in the surface topography as in case 4
Most of engineers use average end area for volume computations as mentioned before. The GIS volume computation methods results and their accuracy percentage rate comparing to the Average end area value are given in Table 2.

According to Table 2, the following results can be outlined:

- Volume computed from surfaces represented as TIN is very close (98.8-99.9\%) to that computed using average end area for all study cases

- The interpolation methods could be divided into 3 groups for the first 3 cases; the first group gave results very close to that of average end area, this includes Natural Neighbor (99.4-99.8\%) and Trend interpolation (99.1-99.9\%). The second group gave results close to average end area method; this group includes Topo to Raster (96.1-99.3\%) and IDW methods (97.0-97.4\%). The third group gave results faraway of average end area; this group includes Kriging (72.5-80.2\%) and Spline interpolation (71.5-77.4\%)

- For case 4 , the closest result to the average end area is that of Trend method (99.2\%) then Topo to Raster (93.3), the faraway result is that of Spline interpolation $(52.4 \%)$

- As an average for the four cases after excluding Trend interpolation, TIN surfaces $(99.3 \%)$ is the best, then Topo to Raster (96.6\%) then Natural Neighbor (96.5\%) while the Spline (69.6\%) and Kriging (79.5\%) are the worst method

The cut and fill volumes needed for grading the surface at $11.0 \mathrm{~m}$ elevation was computed using the surfaces represented as TIN and raster grids. The results were compared to the exact volumes and shown in Table 3 and 4 . The results were also compared to the volumes computed using average end area and shown in Table 5 and 6 .

To compute the exact cut and fill volumes, the surface equation was used to generate Digital Elevation Model (DEM) with $1.0 \mathrm{~m}$ spacing in both $\mathrm{x}$ and $\mathrm{y}$ directions. The DEM was used to generate a TIN surface and its volume was computed and found to be deviated only by $0.2 \%$ from the exact volume. Then the cut and fill volumes to grading the surface at $11.0 \mathrm{~m}$ level was computed and considered to be the exact volumes.

Referring to Table 3 which shows the results compared to the exact ones and knowing that the cut area is a steep slope area and the fill area is a gentle slope area, the following results can be outlined:

- For case 1, 2 and 3, the best results were gotten from Spline and Kriging interpolation. The worst results are from Trend and IDW interpolation. TIN surface, 
Nearest Neighbor and Topo to raster gave almost the same results

- For case 4, when the data points represent the topography well, the results of all methods are improved except for spline interpolation. The best results were gotten from the TIN surface $(95.3 \%)$, Kriging (91.9) and average end area (88.7\%). The poorest results after excluding spline interpolation are that of IDW $(20.1 \%)$ and Nearest Neighbor $(30.1 \%)$.

Table 1. Volume computation approach rate compared to the exact volume

\begin{tabular}{|c|c|c|c|c|c|c|c|c|}
\hline \multirow[b]{2}{*}{ Method } & \multicolumn{2}{|l|}{ Case 1} & \multicolumn{2}{|l|}{ Case 2} & \multicolumn{2}{|l|}{ Case 3} & \multicolumn{2}{|l|}{ Case 4} \\
\hline & Volume $\left(\mathrm{m}^{3}\right)$ & App. rate $\%$ & Volume $\left(\mathrm{m}^{3}\right)$ & App. rate $\%$ & Volume $\left(\mathrm{m}^{3}\right)$ & App. rate $\%$ & Volume $\left(\mathrm{m}^{3}\right)$ & App. rate $\%$ \\
\hline Exact volume & 118800 & - & 118800 & - & 118800 & - & 118800 & - \\
\hline Aver. End Area & 149510 & 74.2 & 141614 & 80.8 & 141614 & 80.8 & 121213 & 98.0 \\
\hline TIN & 151333 & 72.6 & 141808 & 80.6 & 142960 & 79.7 & 120683 & 98.4 \\
\hline IDW & 153877 & 70.5 & 145309 & 77.7 & 145906 & 77.2 & 142420 & 80.1 \\
\hline Kriging & 108428 & 91.3 & 109073 & 91.8 & 113509 & 95.5 & 135618 & 85.8 \\
\hline Natural Neighbor & 150249 & 73.5 & 141908 & 80.5 & 142430 & 80.1 & 136737 & 84.9 \\
\hline Spline & 106832 & 89.9 & 109479 & 92.2 & 109560 & 92.2 & 178970 & 49.4 \\
\hline Topo to Raster & 148536 & 75.0 & 138315 & 83.6 & 136106 & 85.4 & 129295 & 91.2 \\
\hline \multirow[t]{2}{*}{ Trend } & 149393 & 74.2 & 142871 & 79.7 & 142881 & 79.7 & 120253 & 98.8 \\
\hline & -841.7 & & -589.2 & & -796.2 & & -1323.5 & \\
\hline
\end{tabular}

Table 2. Volume computation approach rate compared to the Average End Area volume

\begin{tabular}{|c|c|c|c|c|c|c|c|c|}
\hline \multirow[b]{2}{*}{ Method } & \multicolumn{2}{|l|}{ Case 1} & \multicolumn{2}{|l|}{ Case 2} & \multicolumn{2}{|l|}{ Case 3} & \multicolumn{2}{|l|}{ Case 4} \\
\hline & Volume $\left(\mathrm{m}^{3}\right)$ & App. rate $\%$ & Volume $\left(\mathrm{m}^{3}\right)$ & App. rate $\%$ & Volume $\left(\mathrm{m}^{3}\right)$ & App. rate $\%$ & Volume $\left(\mathrm{m}^{3}\right)$ & App. rate $\%$ \\
\hline Aver. End Area & 149510 & - & 141614 & - & 141614 & - & 121213 & - \\
\hline TIN & 151333 & 98.8 & 141808 & 99.9 & 142960 & 99.0 & 120683 & 99.6 \\
\hline IDW & 153877 & 97.1 & 145309 & 97.4 & 145906 & 97.0 & 142420 & 82.5 \\
\hline Kriging & 108428 & 72.5 & 109073 & 77.0 & 113509 & 80.2 & 135618 & 88.1 \\
\hline Natural Neighbor & 150249 & 99.5 & 141908 & 99.8 & 142430 & 99.4 & 136737 & 87.2 \\
\hline Spline & 106832 & 71.5 & 109479 & 77.3 & 109560 & 77.4 & 178970 & 52.4 \\
\hline Topo to Raster & 148536 & 99.3 & 138315 & 97.7 & 136106 & 96.1 & 129295 & 93.3 \\
\hline \multirow[t]{2}{*}{ Trend } & 149393 & 99.9 & 142871 & 99.1 & 142881 & 99.1 & 120253 & 99.2 \\
\hline & -841.7 & & -589.2 & & -796.2 & & -1323.5 & \\
\hline
\end{tabular}

Table 3. Cut volume computation approach rate compared to the exact cut volume

\begin{tabular}{|c|c|c|c|c|c|c|c|c|}
\hline \multirow[b]{2}{*}{ Method } & \multicolumn{2}{|l|}{ Case 1} & \multicolumn{2}{|l|}{ Case 2} & \multicolumn{2}{|l|}{ Case 3} & \multicolumn{2}{|l|}{ Case 4} \\
\hline & Volume $\left(\mathrm{m}^{3}\right)$ & App. rate $\%$ & Volume $\left(\mathrm{m}^{3}\right)$ & App. rate $\%$ & Volume $\left(\mathrm{m}^{3}\right)$ & App. rate $\%$ & Volume $\left(\mathrm{m}^{3}\right)$ & App. rate $\%$ \\
\hline Exact volume & 27814 & - & 27814 & - & 27814 & - & 27814 & - \\
\hline Aver. End Area & 59767 & -14.9 & 51782 & 13.8 & 54265 & 4.9 & 30951 & 88.7 \\
\hline TIN & 58603 & -10.7 & 49179 & 23.2 & 50282 & 19.2 & 29114 & 95.3 \\
\hline IDW & 61773 & -22.1 & 55632 & 0.0 & 56189 & -2.0 & 50042 & 20.1 \\
\hline Kriging & 15156 & 54.5 & 17669 & 63.5 & 19333 & 69.5 & 25569 & 91.9 \\
\hline Natural Neighbor & 60658 & -18.1 & 52212 & 12.3 & 52640 & 10.7 & 47262 & 30.1 \\
\hline Spline & 18423 & 66.2 & 21020 & 75.6 & 21017 & 75.6 & 82926 & -98.1 \\
\hline Topo to Raster & 60736 & -18.4 & 52120 & 12.6 & 50496 & 18.5 & 40576 & 54.1 \\
\hline Trend & 62373 & -24.3 & 59476 & -13.8 & 58294 & -9.6 & 37639 & 64.7 \\
\hline
\end{tabular}

Table 4. Fill volume computation approach rate compared to the exact fill volume

\begin{tabular}{|c|c|c|c|c|c|c|c|c|}
\hline \multirow[b]{2}{*}{ Method } & \multicolumn{2}{|l|}{ Case 1} & \multicolumn{2}{|l|}{ Case 2} & \multicolumn{2}{|l|}{ Case 3} & \multicolumn{2}{|l|}{ Case 4} \\
\hline & Volume $\left(\mathrm{m}^{3}\right)$ & App. rate $\%$ & Volume $\left(\mathrm{m}^{3}\right)$ & App. rate $\%$ & Volume $\left(\mathrm{m}^{3}\right)$ & App. rate $\%$ & Volume $\left(\mathrm{m}^{3}\right)$ & App. rate $\%$ \\
\hline Exact volume & 29592 & - & 29592 & - & 29592 & - & 29592 & - \\
\hline Aver. End Area & 29057 & 98.2 & 28968 & 97.9 & 28971 & 97.9 & 28538 & 96.4 \\
\hline TIN & 28612 & 96.7 & 28615 & 96.7 & 28569 & 96.5 & 29305 & 99.0 \\
\hline IDW & 26696 & 90.2 & 29124 & 98.4 & 29083 & 98.3 & 26423 & 89.3 \\
\hline Kriging & 25529 & 86.3 & 27396 & 92.6 & 24625 & 83.2 & 8752 & 29.6 \\
\hline Natural Neighbor & 29209 & 98.7 & 29104 & 98.4 & 29009 & 98.0 & 29325 & 99.1 \\
\hline Spline & 30391 & 97.3 & 30341 & 97.5 & 30257 & 97.8 & 22756 & 76.9 \\
\hline Topo to Raster & 31001 & 95.2 & 32605 & 89.8 & 33190 & 87.8 & 30082 & 98.3 \\
\hline Trend & 33895 & 85.5 & 35995 & 78.4 & 35665 & 79.5 & 39643 & 66.0 \\
\hline
\end{tabular}




\begin{tabular}{|c|c|c|c|c|c|c|c|c|}
\hline \multirow[b]{2}{*}{ Method } & \multicolumn{2}{|l|}{ Case 1} & \multicolumn{2}{|l|}{ Case 2} & \multicolumn{2}{|l|}{ Case 3} & \multicolumn{2}{|l|}{ Case 4} \\
\hline & Volume $\left(\mathrm{m}^{3}\right)$ & App. rate \% & Volume $\left(\mathrm{m}^{3}\right)$ & App. rate \% & Volume $\left(\mathrm{m}^{3}\right)$ & App. rate \% & Volume $\left(\mathrm{m}^{3}\right)$ & App. rate $\%$ \\
\hline Aver. End Area & 59767 & - & 51782 & - & 54265 & - & 30951 & - \\
\hline TIN & 58603 & 98.1 & 49179 & 95.0 & 50282 & 92.7 & 29114 & 94.1 \\
\hline IDW & 61773 & 96.6 & 55632 & 92.6 & 56189 & 96.5 & 50042 & 38.3 \\
\hline Kriging & 15156 & 25.4 & 17669 & 34.1 & 19333 & 35.6 & 25569 & 82.6 \\
\hline Natural Neighbor & 60658 & 98.5 & 52212 & 99.2 & 52640 & 97.0 & 47262 & 47.3 \\
\hline Spline & 18423 & 30.8 & 21020 & 40.6 & 21017 & 38.7 & 82926 & -67.9 \\
\hline Topo to Raster & 60736 & 98.4 & 52120 & 99.3 & 50496 & 93.1 & 40576 & 68.9 \\
\hline Trend & 62373 & 95.6 & 59476 & 85.1 & 58294 & 92.6 & 37639 & 78.4 \\
\hline
\end{tabular}

Table 6. Fill volume computation approach rate compared to the Average End Area Fill volume

\begin{tabular}{|c|c|c|c|c|c|c|c|c|}
\hline \multirow[b]{2}{*}{ Method } & \multicolumn{2}{|l|}{ Case 1} & \multicolumn{2}{|l|}{ Case 2} & \multicolumn{2}{|l|}{ Case 3} & \multicolumn{2}{|l|}{ Case 4} \\
\hline & Volume $\left(\mathrm{m}^{3}\right)$ & App. rate $\%$ & Volume $\left(\mathrm{m}^{3}\right)$ & App. rate $\%$ & Volume $\left(\mathrm{m}^{3}\right)$ & App. rate $\%$ & Volume $\left(\mathrm{m}^{3}\right)$ & App. rate $\%$ \\
\hline Aver. End Area & 29057 & - & 28968 & - & 28971 & - & 28538 & - \\
\hline TIN & 28612 & 98.5 & 28615 & 98.8 & 28569 & 98.6 & 29305 & 97.3 \\
\hline IDW & 26696 & 91.9 & 29124 & 99.5 & 29083 & 99.6 & 26423 & 92.6 \\
\hline Kriging & 25529 & 87.9 & 27396 & 94.6 & 24625 & 85.0 & 8752 & 30.7 \\
\hline Natural Neighbor & 29209 & 99.5 & 29104 & 99.5 & 29009 & 99.9 & 29325 & 97.2 \\
\hline Spline & 30391 & 95.4 & 30341 & 95.3 & 30257 & 95.6 & 22756 & 79.7 \\
\hline Topo to Raster & 31001 & 93.3 & 32605 & 87.4 & 33190 & 85.4 & 30082 & 94.6 \\
\hline Trend & 33895 & 83.4 & 35995 & 75.7 & 35665 & 76.9 & 39643 & 61.1 \\
\hline
\end{tabular}

From the results of computing fill volume comparing to the exact volume which shown in Table 4, the following can be outlined:

- For case 1 , the best results for volume calculation were obtained from Natural Neighbor interpolation (98.7\%), Average end area (98.2\%) and Spline $(97.3 \%)$. The worst result was obtained from Trend method $(85.5 \%)$, Kriging method (86.3\%) and IDW (90.2\%)

- For case 2, the best results for volume calculation were obtained from Natural Neighbor interpolation (98.4\%), IDW (98.4\%), Average end area (97.9\%) and Spline (97.5\%). The worst result was obtained from Trend method (78.4\%), Topo to Raster method (89.8\%) and Kriging (92.6\%)

- For case 3, the best results for volume calculation were obtained from IDW (98.3\%), Natural Neighbor interpolation (98.0\%), Average end area (97.9\%) and Spline (97.8\%). The worst result was obtained from Trend method (79.5\%), Kriging (83.2\%) and Topo to Raster method $(87.8 \%)$

- For case 4, the best results for volume calculation were obtained from Natural Neighbor interpolation (99.1\%), TIN surface (99.0\%) and Topo to Raster (98.3\%). The worst result was obtained from Kriging (29.6\%), Trend method (66.0\%) and Spline method (76.9\%)

- As an average for the four cases after excluding Trend interpolation, Natural Neighbor (98.5\%) is the best, then Average end area (97.6\%) and TIN surface $(97.2 \%)$ while the Kriging $(72.9 \%)$ is the worst method. The rest of interpolation methods achieve rates between (92-94\%)
- The best of the GIS techniques for computing cut and fill referring to the exact volumes is Kriging method $(71.4 \%)$ and TIN surface $(64.5 \%)$, while the worst is Trend interpolation (40.8\%) and IDW (46.5\%)

According to Table 5 which compares the results to the average end area result, the following results can be outlined:

- For case 1, 2 and 3, the poorest results were obtained from Spline and Kriging interpolation. The rest of interpolation methods gave results very close to that of Average end area method

- For case 4, the best results are gotten from the TIN surface $(94.1 \%)$, the poorest results after excluding spline interpolation are that of IDW (38.3\%) and Nearest Neighbor (47.3\%)

- As an average for the cut volume for the four cases after excluding Trend interpolation, TIN surface $(94.9 \%)$ is the best, then Topo to Raster $(89.9 \%)$ while the spline (10.6\%) and Kriging (44.4\%) are the worst method. The rest of interpolation methods achieve rates between (81-85\%)

From the results of computing fill volume comparing to the average end area volume which shown in Table 6, the following can be outlined:

The results of all used methods are very close to the average end area method. The poorest results are from Kriging and Trend interpolation especially for case 4.

As an average for the fill volume for the four cases after excluding Trend interpolation, Natural Neighbor 
$(99 \%)$ and TIN surface $(98.3 \%)$ are the best, then IDW $(95.9 \%)$ while Kriging $(74.5 \%)$ is the worst method. The rest of interpolation methods achieve rates between $(90-91.5 \%)$.

The best of the GIS techniques for computing cut and fill referring to the Average end area method is TIN surface $(96.6 \%)$ then Natural Neighbor method $(92.3 \%)$ and, while the worst is Spline $(51.0 \%)$ and Kriging interpolation $(59.5 \%)$.

\section{Conclusion}

In this paper GIS techniques for volume computation are discussed. These techniques depend mainly on generating TIN or raster GRID to represent the surface under which the volume is computed. The accuracy of these techniques were compared to the exact volume and to the volume computed by using average end area method which still used by the majority of the engineers for earthwork volume calculation. The data point distribution and surface characteristics are also discussed. From the results of volume and earthwork computations, the followings could be concluded:

- Point distribution has great effect on volume accuracy especially for steep slope terrain

- Surface topography has great effect of choosing the volume calculation technique. For gentle slope surface, TIN and all interpolation techniques gave results very close to the exact except Kriging and Trend interpolation. For steep slope terrain, Kriging interpolation gave the best results

- The trend interpolation produced negative volume because third-order polynomial fits the surface with two bends to each neighborhood

- Spline interpolation method is sensitive to point density, as the point density decrease the volume accuracy decrease

- The average for the pit excavation volume computation accuracy referred to the exact, Kriging $(91 \%)$ is the best while the IDW $(76 \%)$ is the worst method, the rest of methods are almost the same with (80-83\%) accuracy rate

- The average for the pit excavation volume computation accuracy referred to average end area, TIN surface and Trend interpolation (99.3\%) are the best while Spline $(69.6 \%)$ and Kriging $(79.5 \%)$ are the worst method, the rest of methods are almost the same with (93-96\%) accuracy rate

- Comparing earthwork volume to the average end area method, TIN surface, IDW, Topo to raster and Nearest Neighbor methods gave the best results, while Kriging and Spline methods gave the poorest results for the steep slope terrain. For gentle slope terrain, Kriging and Trend interpolation gave the poorest results

- The average for cut and fill volume computation accuracy referred to the exact, Kriging method $(71.4 \%)$ and TIN surface $(64.5 \%)$ are the best, while the worst is Trend interpolation (40.8\%) and IDW (46.5\%)

- The average for cut and fill volume computation accuracy referred to average end area, TIN surface $(96.6 \%)$ then Natural Neighbor method (92.3\%) and, while the worst is Spline (51.0\%) and Kriging interpolation $(59.5 \%)$

\section{Acknowledgment}

The author gratefully acknowledges the reviewers for their commitment in reviewing the paper.

\section{Ethics}

This work is original and has been done for the first time.

\section{References}

Arun, P.V., 2013. A comparative analysis of different DEM interpolation methods. Egypt. J. Remote Sens. Space Sci., 16: 133-139.

DOI: $10.1016 /$ j.ejrs.2013.09.001

Bao, Y., 2011. Applications of the MapGIS-based digital topographic model on earthwork calculation on land consolidation. Proceedings of the International Conference on Computer Distributed Control and Intelligent Environmental Monitoring, Feb. 19-20, IEEE Xplore Press, Changsha, pp: 1069-1072.

Bhatla, A., S.Y. Choe, O. Fierro and F. Leite, 2012. Evaluation of accuracy of as-built 3D modeling from photos taken by handheld digital cameras. Automat. Construct., 28: 116-127. DOI: $10.1016 /$ j.autcon.2012.06.003

Boissonnat, J.D. and F. Cazals, 2001. Natural neighbor coordinates of points on a surface. Computat. Geometry, 19: 155-173. DOI: 10.1016/S0925-7721(01)00018-9

Burrough, P.A. and R.A. McDonnell, 1998. Principles of Geographical Information Systems. 1st Edn., Oxford University Press, New York, ISBN-10: 0198233655, pp. 356.

Chambers, D.W., 1989. Estimating pit excavation volume using unequal intervals. J. Survey. Eng., 115: 390-401. DOI: 10.1061/(ASCE)0733-9453(1989)115:4(390)

Chen, C.S. and H.C. Lin, 1991. Estimating pit-excavation volume using cubic spline volume formula. J. Survey Eng., 117: 51-66. DOI: 10.1061/(ASCE)0733-9453(1991)117:2(51) 
Cheng, J.C. and L.J. Jiang, 2013. Accuracy comparison of roadway earthwork computation between 3D and 2D methods. Procedia-Soc. Behav. Sci., 96: 1277-1285. DOI: 10.1016/j.sbspro.2013.08.145

Childs, C., 2004. Interpolating surfaces in ArcGIS spatial analyst. Arc User.

Davis, T., 1994. Finite-element volumes. J. Survey. Eng., 120: 94-114.

DOI: 10.1061/(ASCE)0733-9453(1994)120:3(94)

Du, J.C. and H.C. Teng, 2007. 3D laser scanning and GPS technology for landslide earthwork volume estimation. Automat. Construct., 16: 657-663. DOI: 10.1016/j.autcon.2006.11.002

Easa, S., 1988. Estimating pit excavation volume using nonlinear ground profile. J. Survey. Eng., 114: 71-83. DOI: 10.1061/(ASCE)0733-9453(1988)114:2(71)

Easa, S., 1992a. Discussion of "cut and fill calculations by modified average-end-area method" by James W. Epps and Marion W. Corey (September/October, 1990, Vol. 116, No. 5). J. Transp. Eng., 118: 600-601. DOI: 10.1061/(ASCE)0733-947X(1992)118:4(600)

Easa, S., 1992b. Estimating earthwork volumes of curved roadways: Mathematical model. J. Transport. Eng., 118: 834-849. DOI: 10.1061/(ASCE)0733-947X(1992)118:6(834)

Easa, S., 1998. Smooth surface approximation for computing pit excavation volume. J. Survey Eng., 124: $125-133$.

DOI: 10.1061/(ASCE)0733-9453(1998)124:3(125)

Easa, S., 2003. Estimating earthwork volumes of curved roadways: Simulation model. J. Survey Eng., 129: 19-27. DOI: 10.1061/(ASCE)0733-9453(2003)129:1(19)

Epps, J.W. and M.W. Corey, 1990. Cut and fill calculations by modified average-end-area method. J. Transport. Eng., 116: 683-689. DOI: 10.1061/(ASCE)0733-947X(1990)116:5(683)

Garnero, G. and D. Godone, 2013. Comparisons between different interpolation techniques. Proceedings of the International Archives of the Photogrammetry, Remote Sensing and Spatial Information Sciences XL-5/W3, Feb. 27-28, Padua, Italy, pp: 139-144.

Goktepe, A.B. and A.H. Lav, 2003. Method for balancing cut-fill and minimizing the amount of earthwork in the geometric design of highways. J. Transport. Eng., 129: 564-571. DOI: 10.1061/(ASCE)0733-947X(2003)129:5(564)

Hintz, C. and A.P. Vonderohe, 2011. Comparison of earthwork computation methods. Proceedings of the TRB Annual Meeting, (AM' 11), Washington DC.

Hofstra, N., M. Haylock, M. New, P. Jones and C. Frei, 2008. Comparison of six methods for the interpolation of daily, European climate data. J. Geophys. Res., 113: 1-19.

DOI: $10.1029 / 2008 J D 010100$
Hutchinson, M.F., 1989. A new procedure for gridding elevation and stream line data with automatic removal of spurious pits. J. Hydrol., 106: 211-232. DOI: 10.1016/0022-1694(89)90073-5

Kerry, T.S., K.S. Dianne and P.P. James, 2012. Road construction earthwork volume calculation using three-dimensional laser scanning. J. Survey Eng., 138: $96-99$. DOI: 10.1061/(ASCE)SU.1943-5428.0000073

Khalil, R., 2014. Computing pit excavation volume using multiple regression analysis. Int. J. Geomat. Geosci., 5: 43-49.

Kim, E. and P. Schonfeld, 2001. Estimating highway earthwork cross sections using vector and parametric representation. Proceedings of the TRB Annual Meeting, (AM' 01), Washington DC.

Mayer, R. and R. Stark, 1981. Earthmoving logistics. J. Construct. Divis., 107: 297-312.

Moreb, A.A., 1996. Linear programming model for finding optimal roadway grades that minimize earthwork cost. Eur. J. Operat. Res., 93: 148-154. DOI: 10.1016/0377-2217(95)00095-X

Mukherji, B., 2012. Estimating 3D volume using finite elements for pit excavation. J. Survey Eng., 138: 85-91. DOI: $10.1061 /(A S C E) S U .1943-5428.0000059$

Perlavo, M., 2004. Influence of DEM interpolation methods in Drainage Analysis. (report).

Taylor, G., A.Y.T. Kudowor and D. Fairbairn, 2001. Empirical method of error analysis in volume estimation: Monte Carlo simulation under kriging and triangulation. J. Survey Eng., 127: 59-77. DOI: 10.1061/(ASCE)0733-9453(2001)127:2(59)

Xie, Y., T.B. Chen, M. Lei, J. Yang and Q.J. Guo et al., 2011. Spatial distribution of soil heavy metal pollution estimated by different interpolation methods: Accuracy and uncertainty analysis. Chemosphere, 82: 468-476.

DOI: $10.1016 /$ j.chemosphere.2010.09.053

Yanalak, M., 2005. Computing pit excavation volume. J. Survey Eng., 131: 15-19. DOI: 10.1061/(ASCE)0733-9453(2005)131:1(15)

Yilmaz, I., 2009. A research on the accuracy of landform volumes determined using different interpolation methods. Scientific Res. Essay, 4: 1248-1259.

Yilmaz, M., 2007. The effect of interpolation methods in surface definition: An experimental study. Earth Surface Processes Landforms, 32: 1346-1361. DOI: $10.1002 /$ esp. 1473

Yilmaz, M., 2010. Close range photogrammetry in volume computing. Exp. Techniques, 34: 48-54. DOI: $10.1111 /$ j.1747-1567.2009.00476.x 